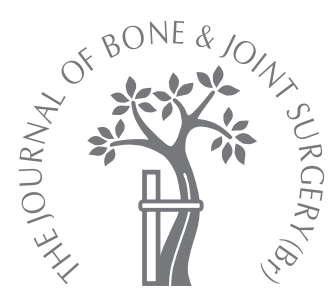

\title{
Effect of lumbar disc replacement on the height of the disc space and the geometry of the facet joints
}

\author{
A CADAVER STUDY
}

\begin{abstract}
K. Kafchitsas, M. Kokkinakis, B. Habermann, M. Rauschmann
\end{abstract}

From Johann Wolfgang Goethe University, Frankfurt, Germany

In a study on ten fresh human cadavers we examined the change in the height of the intervertebral disc space, the angle of lordosis and the geometry of the facet joints after insertion of intervertebral total disc replacements. SB III Charité prostheses were inserted at L3-4, L4-5, and L5-S1. The changes studied were measured using computer navigation sofware applied to CT scans before and after instrumentation.

After disc replacement the mean lumbar disc height was doubled $(p<0.001)$. The mean angle of lordosis and the facet joint space increased by a statistically significant extent $(p<$ 0.005 and $p=0.006$, respectively). By contrast, the mean facet joint overlap was significantly reduced $(p<0.001)$. Our study indicates that the increase in the intervertebral disc height after disc replacement changes the geometry at the facet joints. This may have clinical relevance.

The socio-economic burden of patients with low back pain continues to rise. ${ }^{1}$ There is considerable controversy about the role of surgery in the treatment of chronic back pain associated with lumbar disc degeneration. ${ }^{2}$ The re-establishment of normal spinal anatomy is the aim of any reconstructive surgery and the restoration of normal sagittal balance, the intervertebral disc height and lumbar lordosis are key factors for success after spinal surgery. ${ }^{3}$

The Swedish Lumbar Spine Study Group found that there was a reduction of pain and improved function in patients with severe chronic low back pain after lumbar fusion. ${ }^{4}$ However, another option is disc replacement, the goal of which is to replicate or augment the function of the normal spinal elements both in the quantity and quality of the movement which occurs at the replaced level. ${ }^{5}$ The theoretical advantages of disc replacement over fusion for the treatment of degenerative disc disease include the preservation or restoration of segmental movement, the restoration of the intervertebral architecture and foraminal height, the sparing of adjacent segments from abnormal stress and the restoration of normal local biomechanics. ${ }^{6}$

Cunningham et $\mathrm{al}^{7}$ showed replication of the normal distribution of movement of the intact spine after disc replacement at one level. The results of a recently published fiveyear, prospective, randomised multicentre study showed similar results in terms of clinical outcome between the Charité Artificial Disc (DePuy Spine, Kirkel, Germany) replacement and anterior lumbar interbody fusion. ${ }^{8}$ Although the Charité Artificial Disc has been shown to be successful in relieving pain in most patients, studies have indicated that a significant number do not gain relief from pain. ${ }^{9-12}$ Van Ooij, Oner and Verbout ${ }^{13}$ observed an increase in arthritis of the facet joint at the operated or at an adjacent level, in patients with unsatisfactory results or complications after Charité disc replacement.

The facet joint has been recognised as a source of low back and lower-limb pain since $1911,{ }^{14}$ and it has been widely reported since then that pain syndromes can originate from the facet joint. ${ }^{15-19}$ Biomechanically, this joint plays an important role in load transmission, stabilising the segment in flexion and extension. It is involved in the mechanism of rotational kinematics by restriction of axial rotation ${ }^{20}$ and prevents the forward translation of the lumbar vertebrae, so that the vertebral bodies do not dislocate under the weight of the trunk and the compressive forces placed on the vertebrae when the spine is upright or flexed forward. ${ }^{21}$ Total disc replacement does not restore normal rotational stability of the movement segment which remains increased with a range of $120 \%$ to $140 \%$ above that of the healthy and non operated condition. This rotational instability is additive since a two-level lumbar total disc 
replacement has been shown to have an increase in rotational stability of between $240 \%$ and $260 \%{ }^{22}$

A normal healthy lumbar spine transmits loads between each intervertebral level through the vertebral bodies, the disc and the two facet joints. ${ }^{20,23,24}$ Under normal conditions, between $3 \%$ and $25 \%$ of the segmental load is transmitted through the facet joints. This proportion increases up to $47 \%$ in degenerative joints. ${ }^{25,26}$ The amount of load transferred through the posterior elements is also highly dependent on posture ${ }^{25}$ and increases during extension. ${ }^{26-30}$ The removal of the anterior structural elements with the implant having a mobile instantaneous axis of rotation also relieves the facet loading in extension by $28 \%, 18 \%, 46 \%$ and $28 \%$ when placed centrally, anteriorly, posteriorly, and laterally, respectively. This reduction occurs by easing the posterior translation of the upper vertebra in extension coupled with the migration of the instantaneous axis of rotation anteriorly. ${ }^{31}$

Liu et $\mathrm{al}^{32}$ have hypothesised that an inappropriate increase in the height of an artificial disc is a cause of arthritis of the facet joint.

We have undertaken a study to identify the radiological changes in the geometry of lumbar spinal facet joints caused by the increase in intervertebral disc height and lumbar lordosis after total disc replacement.

\section{Materials and Methods}

Our study was performed on ten cadavers (6 female, 4 male) purchased from Toro University, Las Vegas, Nevada. Their mean age was 71.8 years ( 36 to 88 ) and their mean body mass index was $21.61 \mathrm{~kg} / \mathrm{m}^{2}$ (16 to 24.9 ). Before surgery, CT was undertaken on the lumbar spine of each specimen to exclude the presence of any structural lesions or pronounced spinal or pelvic deformity at the intended levels of operation. None of the cadavers had previous spinal or pelvic surgery. After thawing, they were placed supine with a posteriorly applied radiolucent support to maintain the lumbar lordosis. The CT scans were loaded into the BrainLab navigation software (iPlan 2.0, Brainleb, Feldkirchen, Germany), and an experienced spinal surgeon (MR) identified the 'ideal' placement of the prosthesis planned at each lumbar level.

Implantation. In each cadaver SB III Charité artificial discs (DePuy) were inserted from L4 to S1 giving a total 30 implantations. All the discs were size 3 and in $0 \%$ $0^{\circ}, 0^{\circ} / 5^{\circ}$ and $5^{\circ} / 10^{\circ}$ adjustment for the levels L3-4, L4-5 and L5-S1, respectively with an $8.5 \mathrm{~mm}$ inlay used for all levels. A standard anterior midline retroperitoneal approach was used and a post-operative CT confirmed the placement of the lumbar disc. The surgical technique for implanting an artificial disc resembled that for performing an anterior lumbar interbody fusion. After performing a complete discectomy, the vertebral end-plates were identified and preserved in order to provide mechanical stability and to reduce the potential for subsidence. A pin was positioned in the estimated mid-line of each vertebral body. The correct size of the implant was determined from the preoperative CT scan.

Once implantation had been completed, further CT scans were performed and loaded into the BrainLab navigation software to allow comparison between the planned 'ideal' position and the operative position using the outer spikes of the Charite prosthesis to define the implant.

The placement of the discs was assessed as described by McAfee et al. ${ }^{33}$ Group I, or 'ideal placement' was defined as placement of the disc within $3 \mathrm{~mm}$ of the exact central placement in the coronal and mid-sagittal planes. Group II, or 'suboptimal placement', was defined as that deviating by between $3 \mathrm{~mm}$ and $5 \mathrm{~mm}$ from the central placement in each plane. Group III, or 'poor placement', was placement deviating by $>5 \mathrm{~mm}$ from the placement in each plane.

The change in the intervertebral disc height was measured according to the method of Dabbs and Dabbs ${ }^{34}$ (Fig. 1). The angle of lordosis, the facet joint space and the facet joint overlap were assessed. The angle of lordosis was defined as the angle of the tangential lines to the end-plates of the vertebrae at the level of the implantation of the disc (Fig. 2). The facet joint space was defined as the mean space of four points of the joint using CT cuts of the sagittal view, namely, the most cranial, the most caudal, the widest and the narrowest. With adjustment of contrast, brightness, magnification and threshold it was possible to identify the surface of the articulation (Fig. 3). The facet joint overlap was defined as the distance between the most cranial point of the superior articular process of the lower vertebra and the most caudal point of the inferior articular process of the upper vertebra (Fig. 4).

Statistical analysis. The pre- and post-operative data were compared using the Wilcoxon rank-sum test (paired values). A comparison of left and right facet joint overlap at each level was performed using the paired $t$-test. A p-value $\leq 0.05$ was considered to be statistically significant. Since at every level there are right and left facet joints we also assessed whether the changes in the geometry of the joint anatomy were symmetrical at each level. A significant difference in the joint space or the joint overlap between the right and left sides would suggest asymmetry caused by disc replacement thus leading to additional muscular imbalance.

\section{Results}

Placement of the implants. The mean deviation from the ideal alignment in the coronal plane was $1.4 \mathrm{~mm}$ (SD 1.0). In all, 27 of the 30 instrumented segments did not exceed a deviation of $3 \mathrm{~mm}$. For the three discs not placed in the ideal position in the coronal plane, the maximum deviation was $4.3 \mathrm{~mm}$ and the minimum $0.1 \mathrm{~mm}$. None had poor placement.

The mean deviation from the ideal alignment in the sagittal plane was $1.9 \mathrm{~mm}$ (SD 1.2). In all, 24 of the 30 segments did not exceed a deviation of $3 \mathrm{~mm}$. For the six Charite discs not placed in the ideal placement, the maximum deviation was $4.7 \mathrm{~mm}$ and the minimum $0.2 \mathrm{~mm}$. Again none showed poor placement (Fig. 5). 


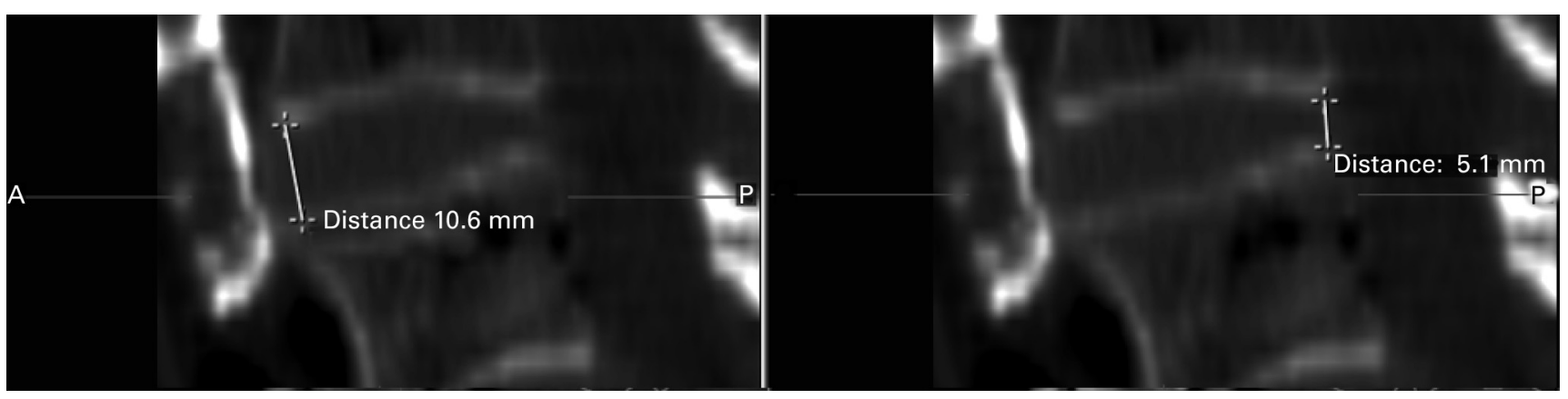

Fig. 1a

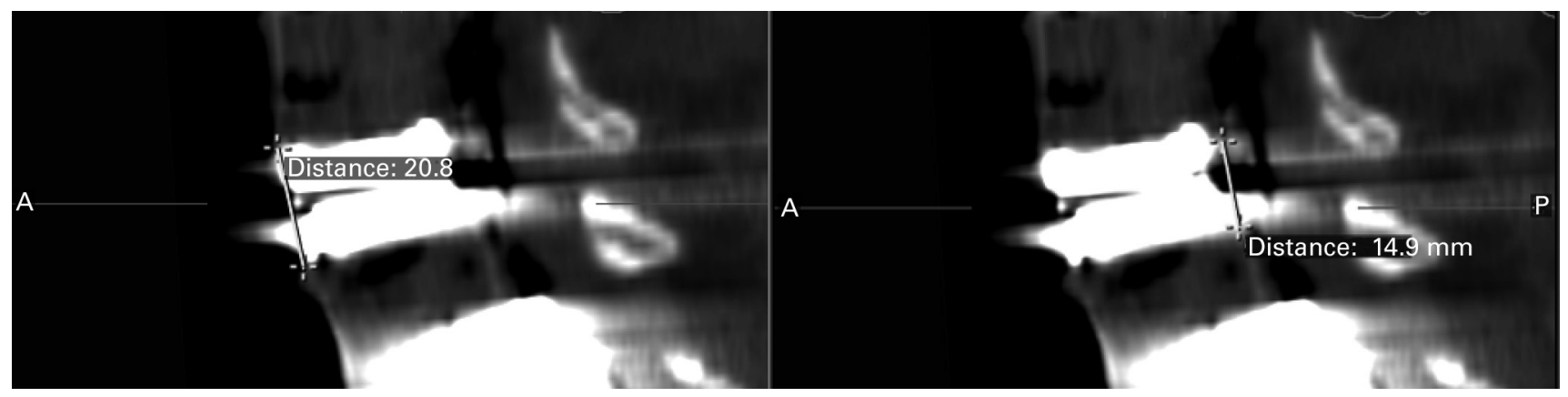

Fig. $1 b$

CT scans showing the change in the height of the disc space from a) the pre-operative level to b) after total disc replacement.

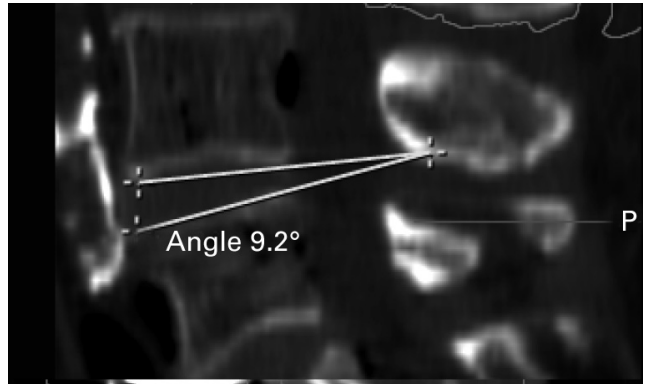

Fig. 2a

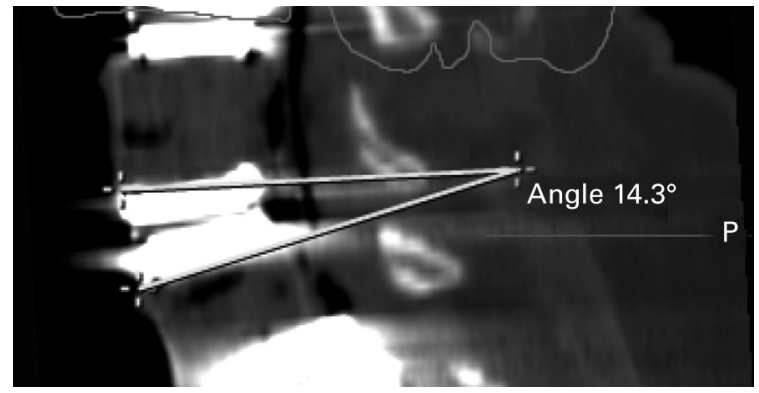

Fig. 2b

CT scans showing measurement of the angle of lordosis a) before and b) after instrumentation.

The pre-operative mean intervertebral disc height at levels L3-4, L4-5 and L5-S1 was 7.8 mm (SD 2.0), $8.0 \mathrm{~mm}$ (SD 2.1) and $8.1 \mathrm{~mm}$ (SD 2.4), respectively. Post-operatively it increased to $15.6 \mathrm{~mm}$ (SD 1.6) at level L3-4, $16.1 \mathrm{~mm}$ (SD 2.5) at level L4-5 and $15.8 \mathrm{~mm}$ (SD 2.2) at level L5-S1. The maximum disc height after instrumentation was $19.7 \mathrm{~mm}$ at L4-5 whereas the maximum before instrumentation did not exceed $13.6 \mathrm{~mm}$. The most extreme increase was from $4.5 \mathrm{~mm}$ pre-operatively to $19 \mathrm{~mm}$ post-operatively. After instrumentation the disc height was significantly increased at all levels (Wilcoxon rank-sum test, L3-4 $\mathrm{p}=0.0009$, L4-5 p -0.0008, L5-S1 p = 0.0006; Fig. 6).
The angle of Lordosis. The pre-operative mean angle of lordosis at levels L3-4, L4-5 and L5-S1 was 6.1 ${ }^{\circ}$ (SD 1.9), 7.8 (SD 2.7) and $13.7^{\circ}$ (SD 3.6), respectively. Post-operatively, it increased to $11.2^{\circ}$ (SD 2.1) at level L3-4, $13.2^{\circ}$ (SD 3.3) at level L4-5 and $25.5^{\circ}$ (SD 3.3) at level L5-S1. The maximum angle of lordosis after instrumentation was $31^{\circ}$ at L5-S1 whereas the maximum before instrumentation did not exceed $17.4^{\circ}$ at L5-S1. The maximum increase was from $7.2^{\circ}$ pre-operatively to $24.3^{\circ}$ at L5-S1 post-operatively. After instrumentation the angle of lordosis was significantly increased at all levels (Wilcoxon rank-sum test, L3-4 $\mathrm{p}=0.004$, L4-5 $\mathrm{p}=0.002$, L5-S1 $\mathrm{p}=0.004$, Fig. 7). 


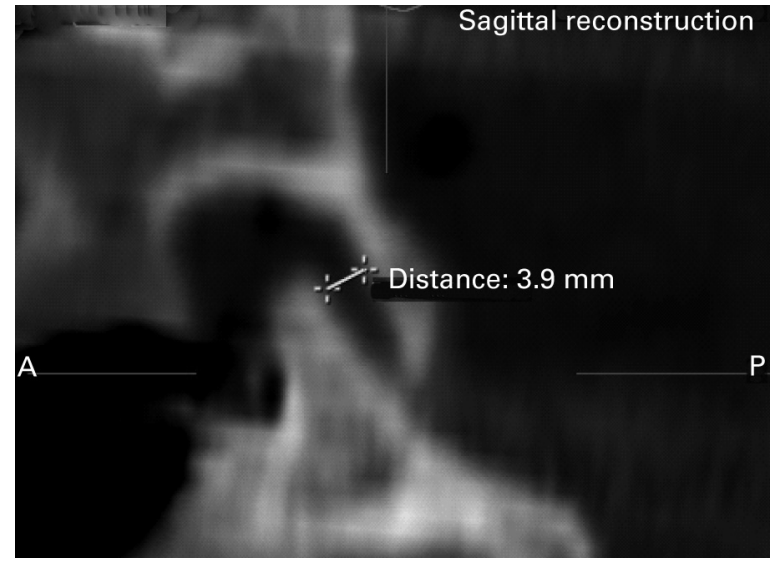

Fig. 3a

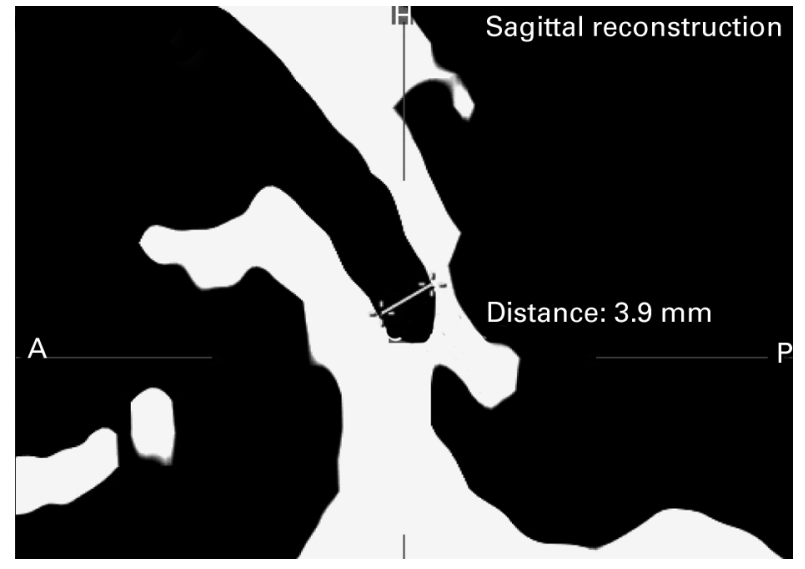

Fig. $3 b$

CT scan showing a) measurement of the facet joint space and b) after adjustment of the threshold.

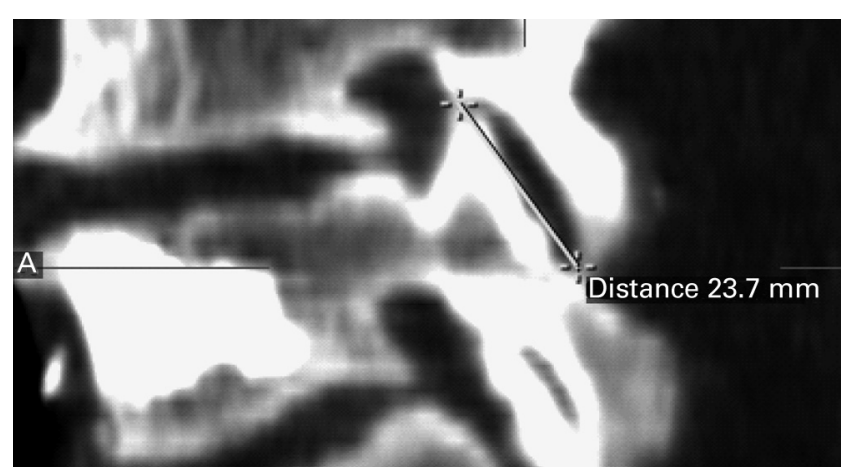

Fig. 4a

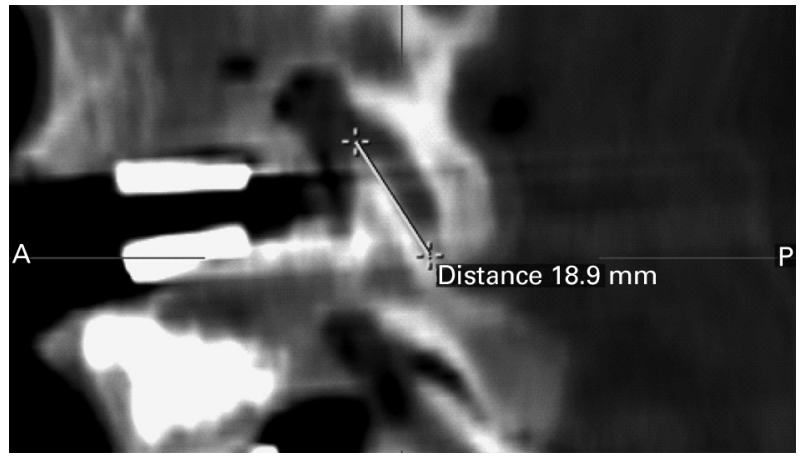

Fig. $4 b$

CT scans showing measurement of the facet joint overlap a) before and b) after instrumentation.

Facet joint space. The pre-operative mean facet joint space at levels L3-4, L4-5 and L5-S1 was $3.0 \mathrm{~mm}$ (SD $1.3 \mathrm{~mm}$ ), $2.8 \mathrm{~mm}$ (SD 0.6) and $2.7 \mathrm{~mm}$ (SD 1.1) $\mathrm{mm}$, respectively. The post-operative mean value increased to $3.4 \mathrm{~mm}$ (SD 1.69) at level L3-4, $3.3 \mathrm{~mm}$ (SD 0.9) at level L4-5 and $2.8 \mathrm{~mm}$ (SD 0.7) at level L5-S1. The maximum facet joint space after instrumentation was $8.1 \mathrm{~mm}$ whereas the maximum before instrumentation did not exceed $7.0 \mathrm{~mm}$. The larger increase was from $3.1 \mathrm{~mm}$ pre-operatively to $5.8 \mathrm{~mm}$ post-operatively. After instrumentation the facet joint space was significantly increased at levels L3-4 and L4-5 (Wilcoxon rank-sum test, L3-4 $\mathrm{p}=0.006$, L4-5 p = 0.002) but not at level L5-S1 (Wilcoxon rank-sum test, L5-S1 p = 0.966, Fig. 8).

Facet joint overlap. The pre-operative mean facet joint overlap at levels L3-4, L4-5 and L5-S1 was $17.9 \mathrm{~mm}$ (SD 3), $18.1 \mathrm{~mm}$ (SD 3.5) and $17.2 \mathrm{~mm}$ (SD 2.9), respectively. The post-operative mean value was decreased to $16.3 \mathrm{~mm}$ (SD 3.7) at level L3-4, $15.7 \mathrm{~mm}$ (SD 3.4) at level L4-5 and $14.9 \mathrm{~mm}$ (SD 2.9) at level L5-S1. The minimum facet joint overlap after instrumentation was $9.4 \mathrm{~mm}$ whereas the minimum before instrumentation was $11.2 \mathrm{~mm}$. The maximum decrease was from $17.1 \mathrm{~mm}$ pre-operatively to $10.6 \mathrm{~mm}$ post-operatively. After instrumentation the facet joint overlap was significantly decreased at all levels (Wilcoxon ranksum test, $\mathrm{p}<0.001$, Fig. 9). No significant asymmetry was observed between the right and left facet joints at any levels before or after total disc replacement ( $t$-test, before L3-4 $\mathrm{p}=0.79, \mathrm{~L} 4-5 \mathrm{p}=0.45, \mathrm{~L} 5-\mathrm{S} 1 \mathrm{p}=0.58$; after: L3-4 p = 0.63, L4-5 $\mathrm{p}=0.96, \mathrm{~L} 5-\mathrm{S} 1 \mathrm{p}=0.67)$.

\section{Discussion}

Lumbar degenerative disc disease may be treated by lumbar fusion with or without instrumentation. ${ }^{35}$ The loss of movement at the fused levels causes additional stress at the adjacent levels which accelerates degenerative disease. ${ }^{36,37}$ This may account for the persistent of symptoms in some patients.

Disc replacement is intended to provide nearly normal biomechanical function at the intervertebral space which theoretically should reduce the mechanical stress at the adjacent levels. ${ }^{38}$ The Charité artificial disc replacement has been reported to be effective in relieving discogenic pain. ${ }^{6}$ However, some patients still have low back pain after surgery. ${ }^{9-11,13}$ 


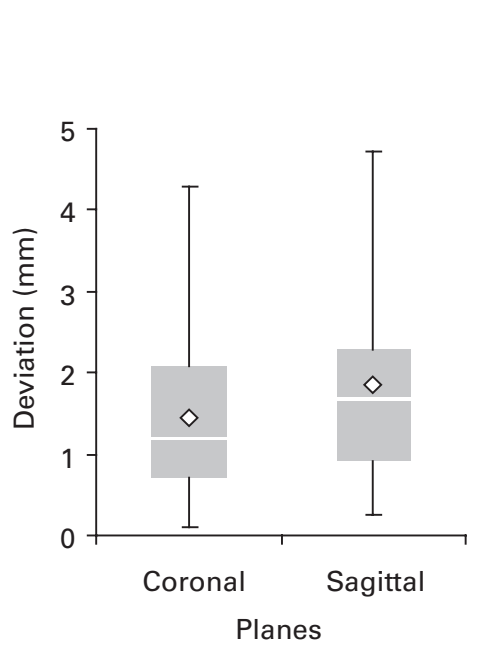

Fig. $5 a$

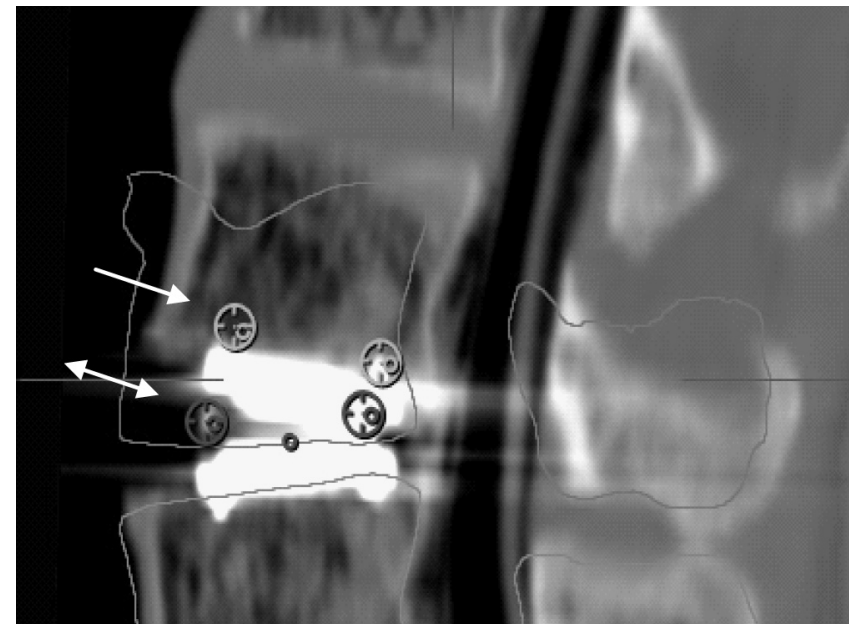

Fig. $5 b$

Figure $5 a-B o x-a n d-w h i s k e r$ plots showing placement of the disc in the sagittal and coronal planes. Figure $5 b-$ The difference between planned (double arrow) and actual (single arrow) position. Box-and-whisker plots display the 25th and 75th percentile (interquartile range) of the data set, standard deviation, median and mean. The plot is for all levels showing deviation from the planned position.

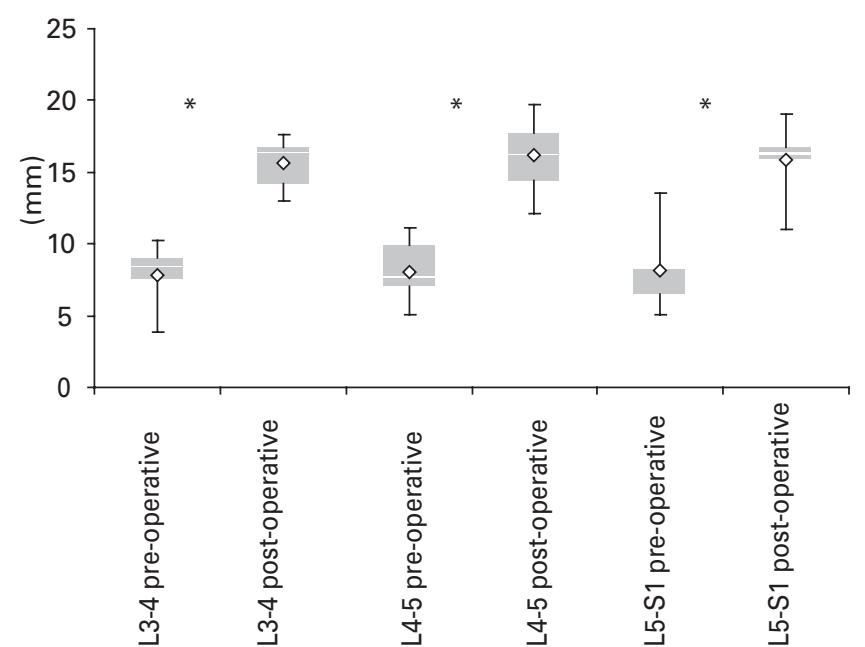

Fig. 6

Box-and-whisker plots of the intervertebral disc height of each level before and after instrumentation.

Biomechanical changes have been reported in the facet joints after total disc replacement. Dooris et $\mathrm{al}^{39}$ suggested that anterior placement of the disc can increase the load on the lumbar facets in compression and extension to 2.5 times above normal. By contrast, posterior placement within the disc space resulted in normal facet loading. Implanted models with a posteriorly placed disc had greater flexibility than both the normal and those with the discs placed anteriorly. ${ }^{39}$ Restoration of the height of the anterior longitudinal ligament reduced pedicle stress, facet load, and rotation in extension to nearly normal levels. ${ }^{39}$

Goel et $\mathrm{al}^{38}$ reported that the Charité artificial disc increased the movement in flexion by approximately $20 \%$

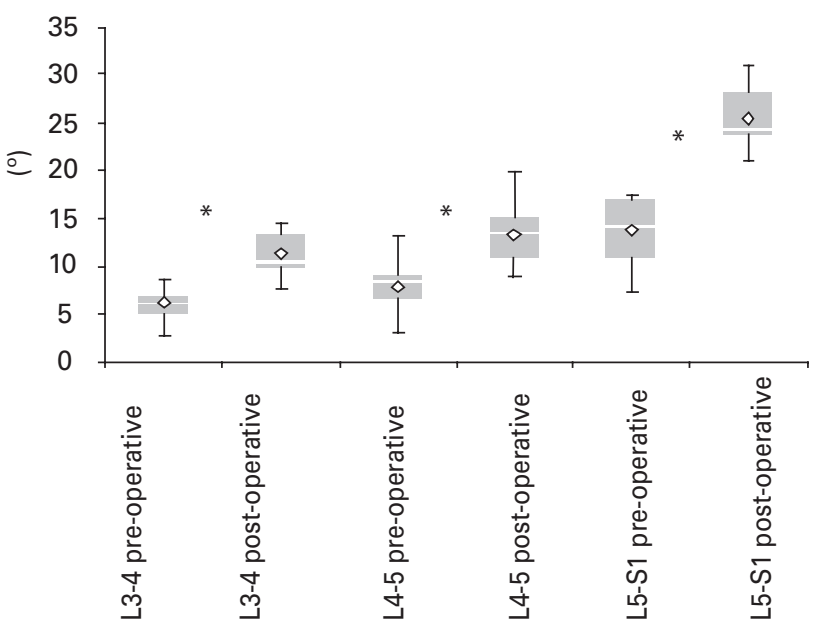

Fig. 7

Box-and-whisker plots of the angle of lordosis at each level before and after instrumentation.

and in extension by approximately $40 \%$ at the L5-S1 level. They found that it slightly increased movement at the implanted level, with a resultant increase in facet loading compared with the adjacent segments and a decrease in movement and loads at the adjacent levels. ${ }^{38}$ However, in the load control mode, the increase in facet loads in extension was around $104 \%$ compared with the normal case. ${ }^{38}$

Liu et $\mathrm{al}^{32}$ in a cadaver study showed that increase in the disc height caused an increase in the facet joint space and a decrease in the facet joint overlap from which it was concluded that the increase in the disc height from disc replacement produced considerable changes in the mechanics of the facet joint. 


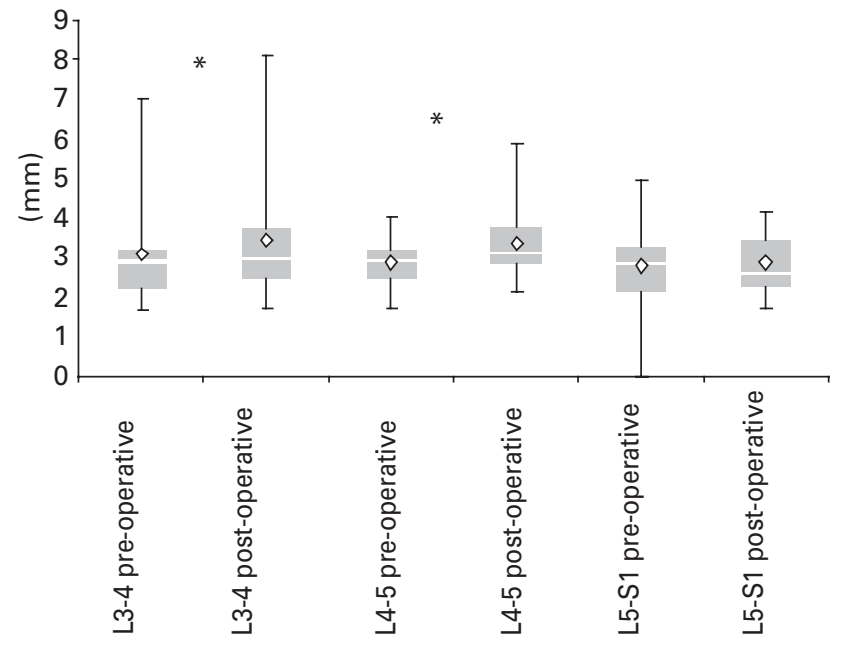

Fig. 8

Box-and-whisker plots of the facet joint space before and after instrumentation.

Our findings agreed with those of Liu et $\mathrm{al}^{32}$ and showed an increase in the disc height at all levels with an increase in the lordosis angle at each level. Additionally, the mean facet joint space was increased at all levels except at L5-S1 where there was no statistically significant change. The mean facet joint overlap also decreased at each level. All these changes disturb the mechanics of the facet joints and contribute to subluxation. Rauschning ${ }^{40}$ reported that subluxation correlated with joint degeneration. The decrease in the facet joint overlap in conjunction with an inappropriate facet load increases the chance of subluxation of the facet joints and thus acclerates the degenerative changes.

Tanno et $\mathrm{al}^{41}$ found that the inferior facet showed most cartilage damage at the superior and inferior poles whereas bony apposition occurred almost exclusively at the inferior pole, where bony contact takes place with the arch of the superior facet during extension. This bony contact is likely to decrease after disc replacement. However, distraction of the facet joints shown by an increase in the joint space could weaken the capsule and accelerate the degenerative changes. $^{41}$

We acknowledge the limitations of our study because of artefacts on the CT reconstruction after total disc replacement. However, for the facet joint space and facet joint overlap these did not present any problem. Proper adjustment of the contrast, brightness and threshold allowed the articular surface of the facet joint or the most caudal and most cranial point of the articular process to be seen clearly. For the disc height artefacts presented a greater problem. Disc height was measured by taking into consideration the anterior and posterior height. This was measured either in the sagittal plane or when this was not possible, in the frontal plane. One or two slices at the beginning and at the end of the bone reconstruction were free from the implant and allowed such measurements to be made.

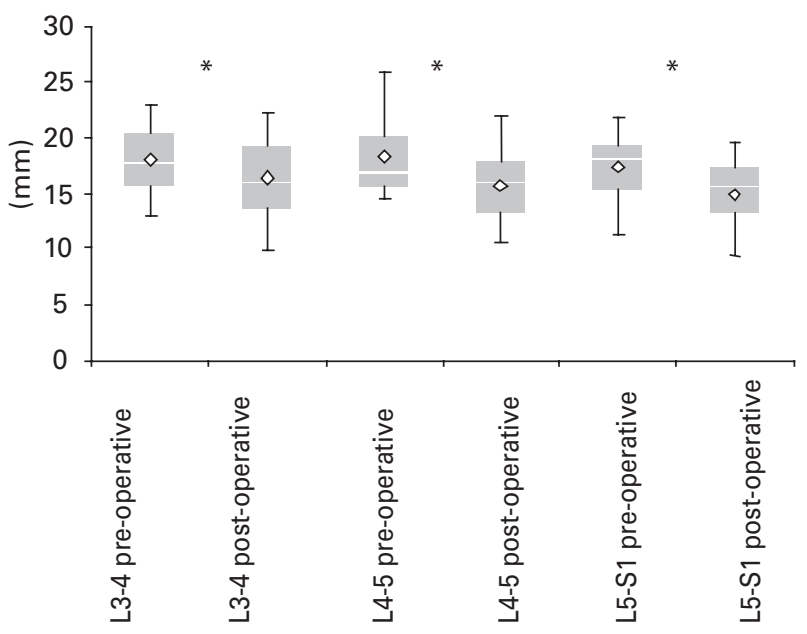

Fig. 9

Box-and-whisker plots of the facet joint overlap before and after the instrumentation.

It was less difficult to overcome artefacts interfering with measurement of the angle of lordosis because this was an angle and not a specific distance. If the caudal end-plate of the vertebra above could not be identified, the tangential line to the cranial end-plate was drawn, since the end-plates of an intact lumbar vertebra should be parallel to each other. For the lower vertebra of the segment, if the cranial end-plate could not be identified, the tangential line to the caudal end-plate was drawn. In rare cases we took the perpendicular lines to the ventral wall of the upper and lower vertebra and measured the angle between them. A further limitation of our study was the uncertainty as to whether the findings from a cadaver study could be extrapolated to the clinical situation. It is not known whether a standing position would change the geometry of the facet joints and lordosis angle. Given the fact that the implant is rigid and that no subsidence of the end-plate occurs, changes to the geometry of the disc space would remain important. If the angle of lordosis remained unchanged, it could be assumed that distraction between the two vertebrae caused by disc replacement would decrease facet joint overlap. In any case, future biomechanical studies should take into consideration the changes in geometry of the disc space and assess any influence on the lordosis angle and facet joints.

Despite the shortcomings of this cadaver model, total disc replacement caused increased loading in the facets depending on the position of the implant ${ }^{42}$ and the latter correlated with the clinical outcome. ${ }^{33}$ Further studies are needed to evaluate the risk of subluxation and further degeneration of the facet joint space after disc replacement. The results of our study suggest a statistical significance in the geometrical characteristics of the disc space and facet joints, but do not establish clinical relevance.

Finally, the disc inlays used $(8.5 \mathrm{~mm})$ were inserted after distraction of the disc space using the least force needed to 
insert them. The muscles of the cadavers did not have the elastic behaviour of those in vivo.

Our findings suggest that any increase in the height of the disc space from the original position produces significant changes in the relative position of the surfaces of the opposing facet joints. In future clinical and biomechanical studies significant changes in the geometry of the disc space and their influence on the relative position of the opposing surfaces of the facets should be considered.

No benefits in any form have been received or will be received from a commer cial party related directly or indirectly to the subject of this article.

\section{References}

1. Mounce K. Back pain. Rheumatology (Oxford) 2002;41:1-5.

2. Mirza SK, Deyo RA. Systematic review of randomized trials comparing lumbar fusion surgery to nonoperative care for treatment of chronic back pain. Spine 2007;32:816-23.

3. Glassman SD, Bridwell K, Dimar JR, et al. The impact of positive sagittal balance in adult spinal deformity. Spine 2005;30:2024-9.

4. Fritzell P, Hägg 0, Wessberg P, Nordwall A, Swedish Lumbar Spine Study Group. Chronic low back pain and fusion: a comparison of three surgical tech niques: a prospective multicenter randomized study from the Swedish lumbar spine study group. Spine 2002;27:1131-41.

5. Crawford NR. Biomechanics of lumbar arthroplasty. Neurosurg Clin N Am 2005;16:595-602.

6. Diwan AD, Parvataneni HK, Khan SN, et al. Current concepts in intervertebral disc restoration. Orthop Clin North Am 2000;31:453-64.

7. Cunningham BW, McAfee PC, Geisler FH, et al. Distribution of in vivo and in vitro range of motion following 1-level arthroplasty with the CHARITE artificial disc compared with fusion. J Neurosurg Spine 2008;8:7-12.

8. Guyer RD, McAfee PC, Banco RJ, et al. Prospective, randomized, multicenter Food and Drug Administration investigational device exemption study of lumbar total disc replacement with the CHARITE artificial disc versus lumbar fusion: fiveyear follow-up. Spine 2009;9:374-86.

9. David R. Long-term results of one-level lumbar arthroplasty: minimum 10-year follow-up of the CHARITE artificial disc in 106 patients. Spine 2007;32:661-6.

10. No authors listed. Ontario Health Technology Policy Assessment on artificia disc replacement for lumbar and cervical degenerative disc disease. An update April 18, 2006. http-://www.health.gov.on.ca/english/providers/program/ohtac/ tech/recommend/rec_adr_041806.pdf (date last accessed 18 January 2010).

11. Lemaire JP, Skalli W, Lavaste F, et al. Intervertebral disc prosthesis: results and prospects for the year 2000. Clin Orthop 1997;337:64-76.

12. Ross R, Mirza AH, Norris HE, Khatri A. Survival and clinical outcome of SB Charite III disc replacement for back pain. J Bone Joint Surg [Br]2007;89-B:785-9.

13. van Ooij A, Oner FC, Verbout AJ. Complications of artificial disc replacement: a report of 27 patients with the SB Charité disc. J Spinal Disord Tech 2003; 16:369-83

14. Goldthwait JE. The lumbosacral articulation: an explanation of many cases of lumbago, sciatica, and paraplegia. Boston Med Surg J 1911;164:365-72.

15. Badgley C. The articular facets in relation to low-back pain and sciatic radiation. $J$ Bone Joint Surg 1941;23:481-96.

16. Carrera GF, Haughton VM, Syvertsen A, Williams AL. Computed tomography of the lumbar facet joints. Radiology 1980;134:145-8.

17. Helbig T, Lee CK. The lumbar facet syndrome. Spine 1988;13:61-4.

18. Lewinnek GE, Warfield CA. Facet joint degeneration as a cause of low back pain. Clin Orthop 1986;213:216-22.
19. Raskin SP. Demonstration of nerve roots on unenhanced computed tomographic scans. J Comput Assist Tomogr 1981:5:281-4.

20. Adams MA, Hutton WC. The mechanical function of the lumbar apophyseal joints. Spine 1983;8:327-30

21. Adams MA, Bogduk N, Burton K, Dolan P. The biomechanics of back pain. Edinburgh: Churchill-Livingstone, 2002:121-3.

22. McAfee PC, Cunningham BW, Hayes V, et al. Biomechanical analysis of rotational motions after disc arthroplasty: implications for patients with adult deformities. Spine 2006;31:152-60.

23. Nägerl H, Kubein-Meesenburg D, Fanghänel J. Elements of a general theory of joints. 7 mechanical structures of the relative motion of adjacent vertebrae. Ann Anat 1992;174:66-75.

24. Putz R. The functional morphology of the superior articular processes of the lumbar vertebrae. J Anat 1985;143:181-7.

25. Nachemson A. Lumbar intradiscal pressure: experimental studies on post-mortem material. Acta Orthop Scand Supp/ 1960;43:1-104.

26. Yang KH, King Al. Mechanism of facet load transmission as a hypothesis for lowback pain. Spine 1984;9:557-65.

27. Dunlop RB, Adams MA, Hutton WC. Disc space narrowing and the lumbar facet joints. J Bone Joint Surg [Br] 1984;66-B:706-10.

28. el-Bohy AA, Yang KH, King Al. Experimental verification of facet load transmission by direct measurement of facet lamina contact pressure. J Biomech 1989:22:931-41.

29. Kalichman L, Hunter DJ. Lumbar facet joint osteoarthritis: a review. Semin Arthritis Rheum 2007;37:69-80.

30. Lorenz M, Patwardhan A, Vanderby R Jr. Load-bearing characteristics of lumbar facets in normal and surgically altered spinal segments. Spine 1983;8:122-30.

31. Moumene M, Geisler FH. Comparison of biomechanical function at ideal and varied surgical placement for two lumbar artificial disc implant designs: mobile-core versus fixed-core. Spine 2007;32:1840-51.

32. Liu J, Ebraheim NA, Haman SP, et al. Effect of the increase in the height of lumbar disc space on facet joint articulation area in sagittal plane. Spine 2006;31:198-202.

33. McAfee PC, Cunningham B, Hosapple G, et al. A prospective, randomized, multicenter Food and Drug Administration investigational device exemption study of lumbar total disc replacement with the CHARITE artificial disc versus lumbar fusion. part II: evaluation of radiographic outcomes and correlation of surgical technique accuracy with clinical outcomes. Spine 2005;30:1576-83.

34. Dabbs V, Dabbs LG. Correlation between disc height narowing and low-back pain. Spine 1990;15:1366-9.

35. Moore KR, Pinto MR, Butler LM. Degenerative disc disease treated with combined anterior and posterior arthrodesis and posterior instrumentation. Spine 2002;27:1680-6

36. Ghiselli G, Wang JC, Bhatia NN, Hsu WK, Dawson EG. Adjacent segment degeneration in the lumbar spine. J Bone Joint Surg [Am] 2004;86-A:1497-503.

37. Park P, Garton HJ, Gala VC, Hoff JT, McGillicuddy JE. Adjacent segment disease after lumbar or lumbosacral fusion: review of the literature. Spine 2004;29:1938-44.

38. Goel VK, Grauer JN, Patel TCh, et al. Effects of charité artificial disc on the implanted and adjacent spinal segments mechanics using a hybrid testing protocol. Spine 2005:30:2755-64.

39. Dooris AP, Goel VK, Grosland M, Gilbertson LG, Wilder DG. Load-sharing between anterior and posterior elements in a lumbar motion segment implanted with an artificial disc. Spine 2001;26:122-9.

40. Rauschning W. Normal and pathologic anatomy of the lumbar root canals. Spine 1987;12:1008-19.

41. Tanno I, Murakami G, Oguma H, et al. Morphometry of the lumbar zygapophyseal facet capsule and cartilage with special reference to degenerative osteoarthritis changes: an anatomical study using fresh cadavers of elderly Japanese and Korean subjects. J Orthop Sci 2004;9:468-77.

42. Rundell SA, Auerbach JD, Balderston RA, Kurtz SM. Total disc replacement positioning affects facet contact forces and vertebral body strains. Spine 2008:33:2510-17. 